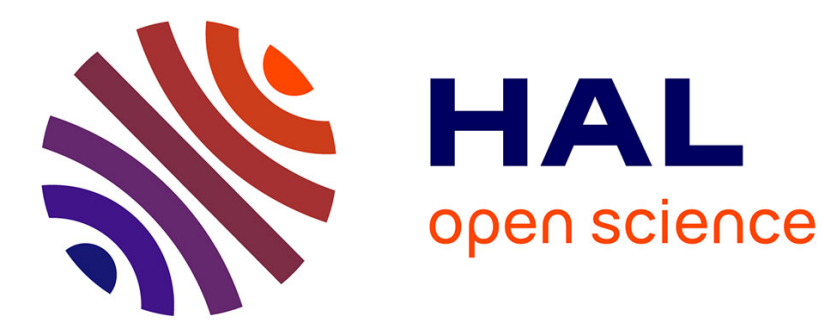

\title{
New Slope-Normalised Global Gully Density and Orientation Maps for Mars
}

\author{
S. Conway, T. N Harrison, R. J Soare, A. Britton, L. J Steele
}

\section{To cite this version:}

S. Conway, T. N Harrison, R. J Soare, A. Britton, L. J Steele. New Slope-Normalised Global Gully Density and Orientation Maps for Mars. The Geological Society, London, Special Publications, 2019, 467 (1), pp.187-197. 10.1144/SP467.3 . hal-02270628

\section{HAL Id: hal-02270628 \\ https://hal.science/hal-02270628}

Submitted on 26 Aug 2019

HAL is a multi-disciplinary open access archive for the deposit and dissemination of scientific research documents, whether they are published or not. The documents may come from teaching and research institutions in France or abroad, or from public or private research centers.
L'archive ouverte pluridisciplinaire HAL, est destinée au dépôt et à la diffusion de documents scientifiques de niveau recherche, publiés ou non, émanant des établissements d'enseignement et de recherche français ou étrangers, des laboratoires publics ou privés. 


\section{New Slope-Normalised Global Gully Density and Orientation Maps for Mars}

2 S. J. Conway ${ }^{1,2 *}$

3 T.N. Harrison ${ }^{3,5}$

$4 \quad$ R. J. Soare ${ }^{4}$

5 A. Britton ${ }^{2,6}$

6 L. J. Steele ${ }^{2}$

$7 \quad{ }^{1}$ Laboratoire de Planétologie et Géodynamique de Nantes- UMR CNRS 6112, 2 rue de la 8 Houssinière - BP 92208, 44322 Nantes Cedex 3, France.

$9 \quad$ 2Department of Physical Sciences, Open University, Milton Keynes, MK7 6AA, UK.

$10{ }^{3}$ Centre for Planetary Science and Exploration, University of Western Ontario, London, N6A 11 5B7, Canada.

$12{ }^{4}$ Department of Geography, Dawson College, 3040 Sherbrooke St. W., Montreal, H3Z 1A4, 13 Canada.

$14{ }^{5}$ Now at Arizona State University, Tempe, AZ 85287, USA

$15{ }^{6}$ Now at, Malin Space Science Systems, San Diego, CA 92191, USA

16 *Correspondence to: susan.conway@univ-nantes.fr

17 Running title: New Gully Density and Orientation Maps for Mars 


\section{Abstract}

19 We re-analyse the global distribution of gullies in order to provide a set of observational constraints that models of gully formation must explain. We validate our results derived from

21 the global data with four detailed case-studies. We show that the availability of steep slopes is 22 an essential factor to consider when assessing the spatial distribution and abundance of gullies.

23 When availability of steep slopes is taken into account it reveals, with a few exceptions, that 24 gullies are found almost uniformly across the whole $30-90^{\circ}$ latitude band. Our analysis also reveals that massive ice deposits are anti-correlated with gullies, and that the undulations in the equatorward limits of the gully distribution could be explained by longitudinal variations in

27 maximum surface temperatures (controlled by variation in surface properties including thermal 28 inertia, and albedo). We find a sharp transition in both hemispheres between pole-facing 29 gullies, which extend from $30^{\circ}$ to $40^{\circ}$ to a more mixed, but dominantly equator-facing orientation of gullies poleward of $40^{\circ}$. We have no definitive explanation for this transition,

31 but based on previous studies we suggest it could be linked to the availability of near-surface 32 ice deposits. 
Kilometre-scale gullies are found ubiquitously on steep slopes at the mid-latitudes of

Mars (e.g., Balme et al., 2006; Dickson et al., 2007; Heldmann et al., 2005; Kneissl et al., 2010). They formed within the last few millions of years (Johnsson et al., 2014; Reiss et al., 2004; Schon et al., 2009a) and resemble water-carved gullies on Earth (Malin and Edgett, 2000). Martian gullies are defined as features comprised of an alcove, channel and debris apron (Malin and Edgett, 2000) and are found on crater walls, knobs, valley walls and sand dunes (e.g., Balme et al., 2006). The distribution of gullies has a clear latitude dependence: they are very rare and maybe even absent altogether, in the equatorial latitudes between $30^{\circ} \mathrm{N}$ and $30^{\circ} \mathrm{S}$ and they are extremely common at latitudes around $35^{\circ} \mathrm{N}$ and $\mathrm{S}$, with the number of gullies observed dropping off towards the poles (e.g., Dickson et al., 2007). It is known that the frequency of steep slopes generally decreases towards the poles (Kreslavsky et al., 2008; Kreslavsky and Head, 2000), which is thought to be partly due to the presence of a draping deposit that mutes the topographic relief at scales of tens to hundreds of metres. The general decrease of gully density from the mid-latitudes to the poles is thought to be partly explained by the decrease in the number of steep slopes (Dickson et al., 2007). However, this has not been quantitatively assessed. In addition, the orientation of gullies is dependent on latitude: at the mid-latitudes gullies tend to face the pole and at high latitudes they have less preference, but some studies have found an equator-facing preference (Bridges and Lackner, 2006; Heldmann et al., 2007).

Together, the latitudinal trends in gully orientation and density suggest an insolation, or climatic, factor is acting in their formation (Costard et al., 2002). However, in order to be able to test different models of gully formation, reliable and precise data are needed on the slope-angle, slope-orientation and latitudinal distribution of gullies.

Here we undertake a re-analysis of the global gully dataset recently published by Harrison et al. (2015) in order to quantify the effect of slope, orientation and latitude on gully 
density. We complement this with similar analyses performed on a more detailed dataset in four regions of interest. The second analysis is performed in order to verify the results derived from the global data.

\section{Approach}

\section{Global data reanalysis}

The global gully dataset compiled by Harrison et al. (2015) comprises a series of points placed on features which host gullies. Each point is attributed with a dominant orientation. We perform the following three analyses: gully density, gully density normalized by steep slopes, and a NS orientation analysis. In all cases we use the standard MOLA 128ppd gridded product, which has a simple cylindrical projection on a spherical Mars datum (radius $3396 \mathrm{~km}$ ). In order to calculate gully density, we use a $250 \mathrm{~km}$ x $250 \mathrm{~km}$ moving window and sum the number of gully points in this window for each pixel. We then take account of the distortion of area caused by the map projection, by dividing this by the true area of the moving window, to produce a number of gully points per $\mathrm{km}^{2}$ (Fig. 1a). Note that, because of the nature of the original mapping, this method of quantifying gully density does not take into account the density/extent of the gully-features themselves, but rather the features that host them. In some cases this may lead to a single gully being given the same "weight" as an extensive suite of gullies. To generate the slope-normalized gully density, instead of dividing by the true area of the moving window, we divide by the area covered by "steep" pixels in the moving window (Fig. 1b). We define "steep" as being pixels with greater than $20^{\circ}$ slope. In order to correct for the influence of the projection in the slope calculation, the fractional slope $\left(S_{m}\right)$ is first calculated in a conformal Mercator projection. These data are then re-projected into the initial simple cylindrical projection and then corrected as follows: $180 / \pi \operatorname{atan}\left(S_{m} / \cos (L)\right)$, where $L$ is the latitude. The number of pixels with slopes greater than or equal to $20^{\circ}$ is then counted per $250 \mathrm{~km} \mathrm{x} 250 \mathrm{~km}$ 
moving window; this count is weighted to take account of the projection, therefore compensating for over-counting towards the pole. Each count is then multiplied by the true area of a pixel for that latitude.

Finally, we calculate the ratio between the frequency of pole-facing gullies and the summed frequency of pole- and equator-facing gullies for a $250 \mathrm{~km}$ x $250 \mathrm{~km}$ moving window in order to better visualize the global trends in gully orientation (Fig. 1c).

\section{Regional site analyses}

Gully slopes are mapped as polygons using ArcGIS and the Java Mission-planning and Analysis for Remote Sensing (JMARS) software package (Christensen et al., 2009) (Fig. 2). The base layer is generated principally by using the Mars Reconnaissance Context camera (CTX) images at $6 \mathrm{~m} /$ pix. Where there is no CTX coverage, poor CTX image quality or deep shadows on slopes, we use the Mars Express High Resolution Stereo Camera (HRSC) at $12.5 \mathrm{~m} / \mathrm{pix}$ and Mars Odyssey's Thermal Emission Imaging Spectrometer visual images (THEMIS-VIS) at $18 \mathrm{~m} / \mathrm{pix}$. The detail of the mapped polygon outlines is simplified to the $100 \mathrm{~m}$-scale, because the aim was to sample the underlying Mars Orbiter Laser Altimeter (MOLA) elevation data, which have a grid-spacing of $~ 463 \mathrm{~m}$.

The MOLA data are projected into a Lambert Conformal Conic projection with standard parallels of $34^{\circ} \mathrm{S} / \mathrm{N}$ and $56^{\circ} \mathrm{S} / \mathrm{N}$ and a centre latitude of $45^{\circ} \mathrm{S} / \mathrm{N}$ preserving the pixel size of $463 \mathrm{~m}$. For Terra Cimmeria a central meridian of $154^{\circ} \mathrm{E}$ is used, $43^{\circ} \mathrm{W}$ for the two Argyre sites and $15^{\circ} \mathrm{W}$ for Acidalia Planitia. We split the Argyre region into two sites along the $42.4^{\circ} \mathrm{E}$ longitude line, to allow us to compare sites with similar spatial extents. We derive slope and aspect from the reprojected MOLA data and then use the polygons to define pixels that contain or do not contain gullies. We considered using the raw MOLA point data to derive slope and aspect. However, erroneous tracks have not been adjusted/removed from this dataset 
(see discussions in: Neumann et al., 2001; Smith et al., 2001; Som, 2008) and such erroneous tracks cause topographic steps, which are exaggerated in derivative data-products. These discontinuities would be more detrimental to our results than the inclusion of interpolated pixels present in the gridded data. In our Lambert Conformal Conic projection the maximum linear distortion is found at $45^{\circ}$ latitude, where it is $<2 \%$, resulting in up to $\pm 0.5^{\circ}$ error in slope at slope of $45^{\circ}$ and $\pm 0.2^{\circ}$ at $10^{\circ}$. This linear distortion results in the real areal extent of a pixel varying by up to $2 \%$ of the nominal $214369 \mathrm{~m}^{2}$ value and hence the calculated pixel densities having an uncertainty of the same magnitude.

\section{Results}

\section{Gully density}

The global gully density map in Fig. 1a reinforces the observations reported in other works, most recently Harrison et al. (2015). In brief, gullies begin to be visible poleward of $\sim 30-35^{\circ}$ in both hemispheres, with the highest densities being found in the southern hemisphere at $\sim 35^{\circ} \mathrm{S}$ in Promethei Terra, Terra Sirenum and Terra Cimmeria, at $\sim 45^{\circ}$ around the rim of the Argyre Basin and high-latitude outliers at $~ 70-80^{\circ} \mathrm{S}$ in the south polar pits (Sisyphi Cavi and Cavi Angusti). For latitudes above $30^{\circ}$, gully density has an inverse relationship with latitude, i.e. gully density tends to decline towards the poles. Densities range up to 19 gully sites per $100 \mathrm{~km}^{2}$ with a mean of 0.64 .

The global trends noted above are supported by our regional studies. The percentage of pixels occupied by gullies in each of the study sites divided up by latitude is shown in Fig. 3a and has a maximum value of $1.4 \%$. Gullied slopes are concentrated in a band between $30^{\circ}$ and $55^{\circ}$ in the Terra Cimmeria (in the southern hemisphere) and Acidalia Planitia (in the northern hemisphere) sites. In the west Argyre site they are found between 35 and $60^{\circ} \mathrm{S}$; by contrast, they are found across a wider latitudinal band from $30^{\circ} \mathrm{S}$ to $60^{\circ} \mathrm{S}$ in the east Argyre site. The 
peak in density in Terra Cimmeria (incidentally coinciding with the Newton Basin) lies in the $35-40^{\circ} \mathrm{S}$ bin and is consistent with the peak in density in the published data from the southern hemisphere study of Heldmann and Mellon (2004). They found that gully density peaked between $33-36^{\circ} \mathrm{S}$, where density was measured as the fraction of MOC (Mars Orbiter Camera) narrow-angle (>1.4 m/pix) images containing clear evidence of gullies. However, at the two Argyre sites the peak in gully density lies within the $45-50^{\circ} \mathrm{S}$ interval, with a particularly large peak in the west Argyre site located in the western Nereidum Montes, the area studied by Raack et al. (2012). Here, the highest regional density of gullied slopes is found. Gullies are of universally low density across the Acidalia Planitia site.

\section{Gully density on steep slopes}

We know that gullies only occur on slopes, because they are formed by gravitational transport, hence a better comparison of gully density is necessary to consider gully density on only sloping terrain - this is shown for our global data in Fig. 1b and for our regional data in Fig. 3b. Compared to the simple density map in Fig. 1a, the slope-normalized-density-map does not show such clear latitudinally distinct regions of gully concentration. Zones with high density are more evenly scattered across the whole distribution. Gullies tend to be denser towards the higher latitudinal limits of their distribution, rather than the mid-latitudes as suggested by the non-normalized data. Densities on steep slopes range up to 1 million gully sites per $100 \mathrm{~km}^{2}$, which is a result of gully sites present in zones with very small areas of steep slopes. The mean density is 940 gully sites per $100 \mathrm{~km}^{2}$ of steeply sloping terrain.

For our regional sites, when the frequency of gullies per latitude is considered in terms of the percentage of pixels with slope-values $\geq 20^{\circ}$ occupied by gullies, instead of simple frequency, the sites now have more similar densities to one another, as suggested by the global data. The percent of pixels occupied by gullies now extends up to $\sim 30 \%$. Most notably the 
158 Acidalia Planitia site now has similar densities to the other three sites and it is now this site which possesses the overall highest density. The gully density is almost uniformly high between $40^{\circ} \mathrm{S}$ and $55^{\circ} \mathrm{S}$ in Terra Cimmeria, with both the Argyre sites having similar densities to Terra Cimmeria in the interval $45-50^{\circ} \mathrm{S}$. The West Argyre site no longer has an unusually high density compared to the other sites, but does retain a significant peak associated with the western Nereidum Montes. In the $35-45^{\circ} \mathrm{S}$ interval in both Argyre sites there is a lower density of slopes with gullies compared to both Terra Cimmeria and the global trends. West Argyre, Terra Cimmeria and Acidalia Planitia have peaks in density in the $45-50^{\circ}$ latitude interval. The previously published global trends in gully density no longer match very well with any of our regional datasets (Fig. 3b).

\section{Gully orientation}

Our global analysis of the ratio of poleward-to-equatorward-facing gully sites agrees in general with previous work (Balme et al., 2006; Dickson et al., 2007; Heldmann and Mellon, 2004; Kneissl et al., 2010), but reveals a sharp transition between pole-facing only gully sites to dominantly equator-facing sites at $\sim 40^{\circ}$. At latitudes equatorward of $40^{\circ}$ almost all gully sites have a poleward facing preference, with some exceptions on the northern rim of Hellas and in the northern hemisphere. In contrast, at latitudes poleward of $40^{\circ}$ the orientation preference tends to be equatorward, but is more mixed, with notable patches having dominant pole-facing preference. Fig. 3c has been filtered to remove zones with low gully density.

Fig. 4 shows gully orientation in our four detailed study regions, for slopes $\geq 10^{\circ}$ and although these data provide more detail, the overall patterns agree with the global data in where from $30^{\circ}$ to $40^{\circ}$ gully sites are oriented towards the pole, $40-45^{\circ}$ is a transition zone and at $>45^{\circ}$ the orientation is predominantly equatorward. West Argyre, also follows this general 
pattern, but has an additional population of pole-facing gullies at latitudes $>40^{\circ} \mathrm{S}$, which was previously identified by Raack et al. (2012).

The sparse nature of northern gullies provides an explanation for the conflicting orientation results of previous studies. Bridges and Lackner (2006) found gullies in 72 MOC images (>1.4 m/pix) and 24 THEMIS-VIS images (18 m/pix) and Heldmann et al. (2007) found gullies in $137 \mathrm{MOC}$ images and both studies reported an equator-facing orientation preference at all latitudes. However, Kneissl et al. (2010) found a transition from pole-facing at $30^{\circ}-40^{\circ} \mathrm{N}$ to equator-facing at $30^{\circ}-40^{\circ} \mathrm{N}$ with contradictory results $>50^{\circ} \mathrm{N}$ using $\mathrm{MOC}$ and HRSC images (12.5 m/pix). et al.et al.From our new analysis it is clear that orientation trends are only clearly visible where there are dense populations of gullies, a criterion which was not used in the previous studies, hence these new density maps are particularly useful where gullies are sparse in the northern mid-latitudes.

\section{Discussion}

\section{Reconsidering factors influencing the global gully density}

Our analyses show that in general the latitudinal distribution of gullies, poleward of $40^{\circ}$, is well-explained by the availability of steep slopes - a relation cited by previous work (e.g., Dickson et al., 2007), but not quantified. Further, our analyses reveal that there are places in this latitudinal zone with steep slopes yet no gullies, or a low density of gullies. In the northern hemisphere, these zones coincide with the scarps of the polar cap, individual impact craters, and Phlegra Montes. In the southern hemisphere these zones coincide with scarps of the polar cap, a few individual impact craters, Promethei and Thyles Rupes, and a zone to the east of Hellas in Promethei Terra. The polar cap scarps are comprised almost pure ice sculpted by wind (Howard, 2000) and hence are not expected to host gullies. The scarps associated with Promethei and Thyles Rupes could be very short hillslopes which therefore might host gullies 
not detectable at the CTX resolution of the Harrison et al. (2015) survey. In Fig. 5a we plot the distribution of Lobate Debris Aprons (LDA) collated by van Gasselt (2007) and of Glacier Like Forms (GLF) from Souness et al. (2012) along with our global gully density and slopedistribution data, and it can be seen that in the vast majority of areas with LDA and GLF have either low gully density or have no mapped gullies. Therefore, the presence of LDA/GLF could explain the relative paucity of gullies in Nereidum Montes, Promethei Terra, Phlegra Montes, Erebus Montes and in Deutero-Protonilus Mensae noted above.

LDA are features where the presence of thick (tens to hundreds of meters) ice has been confirmed in certain examples through analysis of radar data (Holt et al., 2008; Plaut et al., 2009). The present day morphology of LDA and GLF is indicative of relict debris-covered ice (e.g., Arfstrom and Hartmann, 2005; Head et al., 2010; Hubbard et al., 2011; Squyres and Carr, 1986) and these comprise the most substantial ice deposits outside the polar areas (Levy et al., 2014). The presence of substantial ice in the subsurface will increase the thermal inertia of the surface, which could inhibit gully-formation mechanisms related to ice-thaw, or $\mathrm{CO}_{2}$ sublimation. Alternately the morphology of the terrain associated with the presence of LDA and GLF could be inhibiting gully-formation. Another possibility is that such features could cover-up gullies (de Haas et al., 2017). Gullies are known to occur in close association with arcuate ridges (interpreted to be end-moraines; Arfstrom and Hartmann, 2005; Berman et al., 2005; Head et al., 2008) and other signs of degraded "glaciers" (Dickson et al., 2015). Hence, the interrelation between these two features appears to be complex. In any case, this is a new factor that should be taken into account when assessing mechanisms of gully-formation.

Although we do not show the distribution of Concentric Crater Fill (CCF), which are infilled craters also believed to contain extant ice under a lag cover (e.g., Levy et al., 2010; Squyres and Carr, 1986), their distribution covers almost uniformly the whole $30-50^{\circ} \mathrm{N}$ and $\mathrm{S}$ latitude bands (Dickson et al., 2012; Levy et al., 2010). Therefore, conversely to LDA/GLF 
their distribution does not seem to affect the distribution of gullies. CCF does not generally extend up onto the walls of the host craters, thus we might not expect an influence on gullydistribution. Because CCF infills the crater it reduces the total length of the crater-wall (but likely not its slope), so we might expect a reduction of the length of the gullies in such craters. Some of the individual craters without gullies at latitudes $>60^{\circ}$ in both hemispheres are those filled with mounds of polar-cap-like deposits (Conway et al., 2012; Westbrook, 2009). For other individual craters we found no obvious reason that could explain the lack of gullies.

The undulations in the lower latitude boundary of the gully distribution at around $30-35^{\circ} \mathrm{N} / \mathrm{S}$ is not caused by a lack of steep slopes (Fig. 5a), or by the presence of massive ice deposits. As suggested in previous work this boundary could be imposed by the ability to emplace, or to melt surface ice deposits under previous high obliquity climate excursions (Costard et al., 2002; Madeleine et al., 2014). Fig. 5b shows that for any given latitude gullies tend to be present where the annual day mean surface temperature is the highest for that latitude, under current orbital and climate conditions, suggesting ability to melt/sublimate might be the dominant factor, rather than ability to deposit ice. We emphasize that the correlation is not perfect, there are gullies found in "cold spots" on the Tharsis bulge and in Promethei Terra. Additionally we have used surface temperature data derived from a GCM where present data orbital and atmospheric parameters were used. This simulation included the assimilation of Mars Climate Sounder temperature profiles and dust optical depths. The assimilation procedure allows us to obtain the best possible representation of the present-day climate. Full details of the GCM and assimilation procedure can be found in Lewis et al. (2007) and Steele et al. (2014).. However, we feel that it is reasonable to expect that the longitudinal variations in maximum daily average surface temperature should not vary significantly with changes in orbital parameters, providing the surface properties are similar. This is because for a given latitude, the longitudinal temperature variation is mostly driven by changes in the 
albedo and thermal inertia of the regolith (e.g., Mellon and Jakosky, 1993). Areas with the highest mean daily surface temperatures tend to have low albedo and high thermal inertia (and vice versa for the areas with the lowest mean daily surface temperatures). Detailed climate model runs are beyond the scope of this work, but should be performed in the future to verify this apparent correlation.

\section{Orientation}

The latitudinal distribution of gullies overlaps with that of the "Latitude Dependent Mantle" (LDM): a surface-draping deposit thought to comprise an airfall deposit of ice and dust (Kreslavsky and Head, 2002; Mustard et al., 2001). At the mid-latitudes where gullies are most common, the LDM exhibits signs of degradation (pitting, erosional scarps) and becomes more intact with increasing latitude (Milliken et al., 2003; Mustard et al., 2001). The same climatic arguments have been raised to explain the increasing degradation of the LDM towards the equator (e.g., Mustard et al., 2001), as to explain the latitude dependent distribution of gullies. This had led some researchers to link gullies with degradation of the LDM (Bridges and Lackner, 2006; Dickson et al., 2015; Levy et al., 2011; Raack et al., 2012; Schon and Head, 2012). Although no systematic mapping has been performed to ascertain the orientation of the slopes hosting LDM, in the $30-40^{\circ}$ latitude range where pole-facing gullies are observed, Vincendon et al. (2010) noted that the geographical distribution of seasonal $\mathrm{CO}_{2}$ frost indicated subsurface water-ice must be present on pole-facing slopes in this latitude range. Dickson et al. (2015) suggest that the LDM provides an erodible substrate, allowing gully channels to be expressed, therefore the fact that the LDM is generally found on pole-facing slopes in the 30$40^{\circ}$ latitude range, could explain the predominantly pole-facing gully orientations.

However, it is worth noting here that the degraded terrain-muting unit mapped by Mustard et al. (2001) and referred to in many other papers (Kostama et al., 2006; Kreslavsky 
and Head, 2002, 2000; Milliken et al., 2003; Schon et al., 2009b), may not be the same unit as

284

285

286

287 the deposit which hosts the gullies, originally called "pasted-on terrain" by Christensen (2003), but often named LDM in subsequent publications (Conway and Balme, 2014; Dickson et al., 2015; Dickson and Head, 2009; Levy et al., 2011, 2009). Conway and Balme (2014) noted the polygonally patterned and often ribbed unit into which gullies incise is substantially thicker (up to $30 \mathrm{~m}$ ) than the LDM measured on the plains (around several metres; Kreslavsky and Head, 2002; Mustard et al., 2001; Schon et al., 2009b). Soare et al. (2017) have also noted that the polygonally-patterned unit into which gullies incise is located stratigraphically below the LDM found on the inter-crater plains and exhibits a different suite of degradation features from the LDM. This "pasted-on" unit could be related to the mid-latitude crater asymmetry noted by Conway and Mangold (2013), or incipient formation of glacier-like-forms (e.g., Head et al., 2008). In addition, many gully systems do not originate in areas covered in "LDM" (Aston et al., 2011) and there are also examples of gullies present where no evidence for "LDM" is found at all (Johnsson et al. 2014, de Haas et al., 2015a, 2015b).

\section{Conclusions}

We conclude that the availability of steep slopes must be taken into account to perform a fair assessment of global gully density.

From these analyses we conclude that any model of gully formation would have to explain the following:

- The onset of gully forming processes at $\sim 30^{\circ} \mathrm{N} / \mathrm{S}$ and the undulations in that boundary.

- The generally uniform gully forming potential in the whole $30-55^{\circ}$ latitude band.

- Local paucity of gullies (e.g. Promethei Terra), which appear to coincide with massive ice deposits. 
- The sharp transition from almost uniquely pole-facing to dominantly equator-facing, being consistently located at $\sim 40^{\circ} \mathrm{N} / \mathrm{S}$.

309

310 Acknowledgements

311 We thank Ginny Gulick and one anonymous reviewer for their helpful comments with which

312 we improved the manuscript. SJC acknowledges funding from the Leverhulme Trust in support

313 of this work (grant number RPG-397) and support from the French Space Agency, CNES. 


\section{References cited:}

Arfstrom, J., Hartmann, W.K., 2005. Martian flow features, moraine-like ridges, and gullies: Terrestrial analogs and interrelationships. Icarus 174, 321-335.

Aston, A.H., Conway, S.J., Balme, M.R., 2011. Identifying Martian gully evolution. Geol. Soc. Lond. Spec. Publ. 356, 151-169. doi:10.1144/SP356.9

Balme, M., Mangold, N., Baratoux, D., Costard, F., Gosselin, M., Masson, P., Pinet, P., Neukum, G., 2006. Orientation and distribution of recent gullies in the southern hemisphere of Mars: Observations from High Resolution Stereo Camera/Mars Express (HRSC/MEX) and Mars Orbiter Camera/Mars Global Surveyor (MOC/MGS) data. J. Geophys. Res. Planets 111, doi:10.1029/2005JE002607.

Berman, D.C., Hartmann, W.K., Crown, D.A., Baker, V.R., 2005. The role of arcuate ridges and gullies in the degradation of craters in the Newton Basin region of Mars. Icarus 178, 465-486.

Bridges, N.T., Lackner, C.N., 2006. Northern hemisphere Martian gullies and mantled terrain: Implications for near-surface water migration in Mars' recent past. J. Geophys. Res. Planets 111, 09014. doi:10.1029/2006JE002702

Christensen, P.R., 2003. Formation of recent martian gullies through melting of extensive water-rich snow deposits. Nature $422,45-48$.

Christensen, P.R., Engle, E., Anwar, S., Dickenshied, S., Noss, D., Gorelick, N., Weiss-Malik, M., 2009. JMARS-A Planetary GIS, in: AGU Fall Meeting Abstracts. p. 06.

Conway, S.J., Balme, M.R., 2014. Decametre-thick remnant glacial ice deposits on Mars. Geophys. Res. Lett. 41, 5402-5409. doi:10.1002/2014GL060314

Conway, S.J., Hovius, N., Barnie, T., Besserer, J., Le Mouélic, S., Orosei, R., Read, N.A., 2012. Climatedriven deposition of water ice and the formation of mounds in craters in Mars' north polar region. Icarus 220, 174-193. doi:10.1016/j.icarus.2012.04.021

Conway, S.J., Mangold, N., 2013. Evidence for Amazonian mid-latitude glaciation on Mars from impact crater asymmetry. Icarus 225, 413-423. doi:10.1016/j.icarus.2013.04.013 
Costard, F., Forget, F., Mangold, N., Peulvast, J.P., 2002. Formation of recent Martian debris flows by melting of near-surface ground ice at high obliquity. Science $295,110-113$. doi:10.1126/science.1066698

de Haas, T., Conway, S.J., Butcher, F.E.G., Levy, J.S., Grindrod, P.M., Balme, M.R., Goudge, T.A., 2017. Time will tell: temporal evolution of Martian gullies and paleoclimatic implications. Geol. Soc. Lond. Spec. Publ. this volume, in review.

de Haas, T., Conway, S.J., Krautblatter, M., 2015a. Recent (Late Amazonian) enhanced backweathering rates on Mars: Paracratering evidence from gully alcoves: LATE AMAZONIAN BACKWEATHERING RATES. J. Geophys. Res. Planets 120, 2169-2189. doi:10.1002/2015JE004915

de Haas, T., Hauber, E., Conway, S.J., van Steijn, H., Johnsson, A., Kleinhans, M.G., 2015b. Earth-like aqueous debris-flow activity on Mars at high orbital obliquity in the last million years. Nat. Commun. 6. doi:10.1038/ncomms8543

Dickson, J.L., Head, J.W., 2009. The formation and evolution of youthful gullies on Mars: Gullies as the late-stage phase of Mars' most recent ice age. Icarus 204, 63-86.

Dickson, J.L., Head, J.W., Fassett, C.I., 2012. Patterns of accumulation and flow of ice in the midlatitudes of Mars during the Amazonian. Icarus 219, 723-732. doi:10.1016/j.icarus.2012.03.010

Dickson, J.L., Head, J.W., Goudge, T.A., Barbieri, L., 2015. Recent climate cycles on Mars: Stratigraphic relationships between multiple generations of gullies and the latitude dependent mantle. Icarus 252, 83-94. doi:10.1016/j.icarus.2014.12.035

Dickson, J.L., Head, J.W., Kreslavsky, M., 2007. Martian gullies in the southern mid-latitudes of Mars: Evidence for climate-controlled formation of young fluvial features based upon local and global topography. Icarus 188, 315-323. 
Harrison, T.N., Osinski, G.R., Tornabene, L.L., Jones, E., 2015. Global Documentation of Gullies with the Mars Reconnaissance Orbiter Context Camera and Implications for Their Formation. Icarus 252, 236-254. doi:10.1016/j.icarus.2015.01.022

Head, J.W., Marchant, D.R., Dickson, J.L., Kress, A.M., Baker, D.M., 2010. Northern mid-latitude glaciation in the Late Amazonian period of Mars: Criteria for the recognition of debriscovered glacier and valley glacier landsystem deposits. Earth Planet. Sci. Lett. 294, 306-320. doi:DOI: 10.1016/j.epsl.2009.06.041

Head, J.W., Marchant, D.R., Kreslavsky, M.A., 2008. Formation of gullies on Mars: Link to recent climate history and insolation microenvironments implicate surface water flow origin. Proc. Natl. Acad. Sci. U. S. A. 105, 13258-13263.

Heldmann, J.L., Carlsson, E., Johansson, H., Mellon, M.T., Toon, O.B., 2007. Observations of martian gullies and constraints on potential formation mechanisms II. The northern hemisphere. Icarus $188,324-344$.

Heldmann, J.L., Mellon, M.T., 2004. Observations of martian gullies and constraints on potential formation mechanisms. Icarus 168, 285-304.

Heldmann, J.L., Toon, O.B., Pollard, W.H., Mellon, M.T., Pitlick, J., McKay, C.P., Andersen, D.T., 2005. Formation of Martian gullies by the action of liquid water flowing under current Martian environmental conditions. J Geophys Res-Planets 110, doi:10.1029/2004JE002261.

Holt, J.W., Safaeinili, A., Plaut, J.J., Head, J.W., Phillips, R.J., Seu, R., Kempf, S.D., Choudhary, P., Young, D.A., Putzig, N.E., Biccari, D., Gim, Y., 2008. Radar Sounding Evidence for Buried Glaciers in the Southern Mid-Latitudes of Mars. Science 322, 1235-1238.

Howard, A. D. (2000). The role of eolian processes in forming surface features of the Martian polar layered deposits. Icarus, 144(2), 267-288.

Hubbard, B., Milliken, R.E., Kargel, J.S., Limaye, A., Souness, C., 2011. Geomorphological characterisation and interpretation of a mid-latitude glacier-like form: Hellas Planitia, Mars. Icarus 211, 330-346. doi:10.1016/j.icarus.2010.10.021 
Johnsson, A., Reiss, D., Hauber, E., Hiesinger, H., Zanetti, M., 2014. Evidence for very recent meltwater and debris flow activity in gullies in a young mid-latitude crater on Mars. Icarus 235, 37-54. doi:10.1016/j.icarus.2014.03.005

Kneissl, T., Reiss, D., van Gasselt, S., Neukum, G., 2010. Distribution and orientation of northernhemisphere gullies on Mars from the evaluation of HRSC and MOC-NA data. Earth Planet. Sci. Lett. 294, 357-367. doi:j.epsl.2009.05.018

Kostama, V.-P., Kreslavsky, M.A., Head, J.W., 2006. Recent high-latitude icy mantle in the northern plains of Mars: Characteristics and ages of emplacement. Geophys Res Lett 33, L11201. doi:10.1029/2006GL025946

Kreslavsky, M.A., Head, J.W., 2002. Mars: Nature and evolution of young latitude-dependent waterice-rich mantle. Geophys. Res. Lett. 29, 14-1. doi:10.1029/2002GL015392

Kreslavsky, M.A., Head, J.W., 2000. Kilometer-scale roughness of Mars: Results from MOLA data analysis. J. Geophys. Res. 105, 26695-26712. doi:10.1029/2000JE001259

Kreslavsky, M.A., Head, J.W., Marchant, D.R., 2008. Periods of active permafrost layer formation during the geological history of Mars: Implications for circum-polar and mid-latitude surface processes. Planet. Space Sci. 56, 289-302. doi:10.1016/j.pss.2006.02.010

Levy, J., Head, J.W., Marchant, D.R., 2010. Concentric crater fill in the northern mid-latitudes of Mars: Formation processes and relationships to similar landforms of glacial origin. Icarus 209, 390-404. doi:10.1016/j.icarus.2010.03.036

Levy, J.S., Fassett, C.I., Head, J.W., Schwartz, C., Watters, J.L., 2014. Sequestered glacial ice contribution to the global Martian water budget: Geometric constraints on the volume of remnant, midlatitude debris-covered glaciers. J. Geophys. Res. Planets 119, 2014 JE004685. doi:10.1002/2014JE004685

Levy, J.S., Head, J.W., Marchant, D.R., 2011. Gullies, polygons and mantles in Martian permafrost environments: cold desert landforms and sedimentary processes during recent Martian geological history. Geol. Soc. Lond. Spec. Publ. 354, 167-182. doi:10.1144/SP354.10 
Levy, J.S., Head, J.W., Marchant, D.R., Dickson, J.L., Morgan, G.A., 2009. Geologically recent gullypolygon relationships on Mars: Insights from the Antarctic dry valleys on the roles of permafrost, microclimates, and water sources for surface flow. Icarus 201, 113-126.

Lewis, S. R., Read, P. L., Conrath, B. J., Pearl, J. C., Smith, M. D., 2007. Assimilation of Thermal Emission Spectrometer atmospheric data during the Mars Global Surveyor aerobraking period. Icarus 192, 327-347.

Madeleine, J.-B., Head, J.W., Forget, F., Navarro, T., Millour, E., Spiga, A., Colaïtis, A., Määttänen, A., Montmessin, F., Dickson, J.L., 2014. Recent Ice Ages on Mars: The role of radiatively active clouds and cloud microphysics. Geophys. Res. Lett. n/a-n/a. doi:10.1002/2014GL059861

Malin, M.C., Edgett, K.S., 2000. Evidence for recent groundwater seepage and surface runoff on Mars. Science 288, 2330-2335. doi:10.1126/science.288.5475.2330

Mellon, M.T., Jakosky, B.M., 1993. Geographic variations in the thermal and diffusive stability of ground ice on Mars. J. Geophys. Res. 98, 3345. doi:10.1029/92JE02355

Milliken, R.E., Mustard, J.F., Goldsby, D.L., 2003. Viscous flow features on the surface of Mars: Observations from high-resolution Mars Orbiter Camera (MOC) images. J Geophys Res 108, doi:10.1029/2002JE002005.

Mustard, J.F., Cooper, C.D., Rifkin, M.K., 2001. Evidence for recent climate change on Mars from the identification of youthful near-surface ground ice. Nature 412, 411-414. doi:10.1038/35086515

Neumann, G.A., Rowlands, D.D., Lemoine, F.G., Smith, D.E., Zuber, M.T., 2001. Crossover analysis of Mars Orbiter Laser Altimeter data. J. Geophys. Res. Planets 106, 23753-23768. doi:10.1029/2000JE001381

Plaut, J.J., Safaeinili, A., Holt, J.W., Phillips, R.J., Head, J.W., Seu, R., Putzig, N.E., Frigeri, A., 2009. Radar evidence for ice in lobate debris aprons in the mid-northern latitudes of Mars. Geophys. Res. Lett. 36, 02203. 
Raack, J., Reiss, D., Hiesinger, H., 2012. Gullies and their relationships to the dust-ice mantle in the northwestern Argyre Basin, Mars. Icarus 219, 129-141. doi:10.1016/j.icarus.2012.02.025

Reiss, D., van Gasselt, S., Neukum, G., Jaumann, R., 2004. Absolute dune ages and implications for the time of formation of gullies in Nirgal Vallis, Mars. J Geophys Res-Planets 109, doi:10.1029/2004JE002251.

Schon, S.C., Head, J.W., 2012. Gasa impact crater, Mars: Very young gullies formed from impact into latitude-dependent mantle and debris-covered glacier deposits? Icarus 218, 459-477. doi:10.1016/j.icarus.2012.01.002

Schon, S.C., Head, J.W., Fassett, C.I., 2009a. Unique chronostratigraphic marker in depositional fan stratigraphy on Mars: Evidence for ca. 1.25 Ma gully activity and surficial meltwater origin. Geology 37, 207-210. doi:10.1130/g25398a.1

Schon, S.C., Head, J.W., Milliken, R.E., 2009b. A recent ice age on Mars: Evidence for climate oscillations from regional layering in mid-latitude mantling deposits. Geophys Res Lett 36, doi:10.1029/2009GL038554. doi:10.1029/2009GL038554

Smith, D.E., Zuber, M.T., Frey, H.V., Garvin, J.B., Head, J.W., Muhleman, D.O., Pettengill, G.H., Phillips, R.J., Solomon, S.C., Zwally, H.J., Banerdt, W.B., Duxbury, T.C., Golombek, M.P., Lemoine, F.G., Neumann, G.A., Rowlands, D.D., Aharonson, O., Ford, P.G., Ivanov, A.B., Johnson, C.L., McGovern, P.J., Abshire, J.B., Afzal, R.S., Sun, X., 2001. Mars Orbiter Laser Altimeter: Experiment summary after the first year of global mapping of Mars. J. Geophys. Res. Planets 106, 23689-23722. doi:10.1029/2000JE001364

Soare, R.J., Conway, S.J., Gallagher, C., Dohm, J.M., 2017. Ice-rich (periglacial) vs icy (glacial) depressions in the Argyre region, Mars: a proposed cold-climate dichotomy of landforms. Icarus 282, 70-83. doi:10.1016/j.icarus.2016.09.009

Som, 2008. The Mars Orbiter Laser Altimeter dataset: Limitations and improvements. Mars J. 4, 1426. doi:10.1555/mars.2008.0002 

analysis of Martian glacier-like forms. Icarus 217, 243-255. doi:10.1016/j.icarus.2011.10.020

Squyres, S.W., Carr, M.H., 1986. Geomorphic Evidence for the Distribution of Ground Ice on Mars. Science 231, 249-252. doi:10.1126/science.231.4735.249

Steele, L. J., Lewis, S. R., Patel, M. R., 2014. The radiative impact of water ice clouds from a reanalysis of Mars Climate Sounder data. Geophys. Res. Lett. 41, 4471-4478. Near-tropical subsurface ice on Mars. Geophys. Res. Lett. 37, doi:10.1029/2009GL041426. doi:10.1029/2009gl041426

Westbrook, O.W., 2009. Crater ice deposits near the south pole of Mars (Masters). Massachusetts Institute of Technology, Cambridge, MA. 
Figure 1: Maps derived from re-analysis of the Harrison et al. (2015) gully database and the

481 global MOLA topography data. A) Point-density of gullies in number sites per $100 \mathrm{~km}^{2}$. B) Point-density of gullies in number sites per $100 \mathrm{~km}^{2}$ of steeply sloping terrain, where "steep" is defined as $\geq 20^{\circ}$. This representation gives an unbiased view of the distribution of gullies and should be used in preference to A). C) The ratio between the frequency of pole-facing gullies and the summed frequency of pole- and equator-facing gullies, where $1=100 \%$ polefacing and $0=100 \%$ equator-facing. Pink outlines are the four sites studied in greater detail, EA $=$ East Argyre, $\mathrm{WA}=$ West Argyre, $\mathrm{TC}=$ Terra Cimmeria and AP $=$ Acidalia Planitia.

Figure 2: Digitisation of gullies as polygons. CTX image P14_006572_1367_XN_43S051W, with colour-coded MOLA topography in the background and digitised gullies as pink outlines. The black and white box in the top-left shows the size of a MOLA pixel for illustration.

Figure 3: Top: Percent of pixels with gullies per latitude bin per region. Bottom: Percent of gully occupation on pixels with slopes $>20^{\circ}$, per latitude bin, per region. Map projected data were used to calculate the number of pixels, hence the real areal extent could be $\pm 2 \%$ the value represented by these bars (and therefore is too small to be visually represented). The grey line is the normalized southern-hemisphere frequency of gullies taken from Dickson and Head (2009), based on data by Heldmann and Mellon (2004), who calculated the percentage of Mars Orbiter Camera images with gullies per $3^{\circ}$ latitude bin. 
502 Figure 4: Orientation (aspect) of MOLA pixels containing gullies, per latitude, for the four

503 detailed study sites. Red numbers indicate the value of the outer-ring on the polar-axis, which

504 is the relative frequency of gullies on slopes $>10^{\circ}$ for any given orientation in that latitude

505 bin (we used a $10^{\circ}$ threshold in this case, otherwise the number of samples per orientation

506 was too small). Therefore gully density ranges between 2.5 and $25 \%$. Note: the northern

507 hemisphere site Acidalia Planum has been mirrored across the $\mathrm{x}$-axis, so that pole-facing

508 slopes are oriented down-page, for ease of comparison with the southern hemisphere sites.

509

510 Figure 5: Exploration of variables that may explain the global gully distribution. A) Slopes,

511 LDA, GLF and gullies. Masked out in white are areas with few steep slopes (i.e. <

$51215,000,000$ "steep" slopes per $\mathrm{km}^{2}$ ). B) A map of the year-maximum day-average surface

513 temperature, derived using a similar methodology to Kreslavsky et al. (2008), where the

514 temperatures have been re-scaled, so that $1=$ maximum temperature for each latitude and 0

$515=$ minimum temperature for each latitude. 


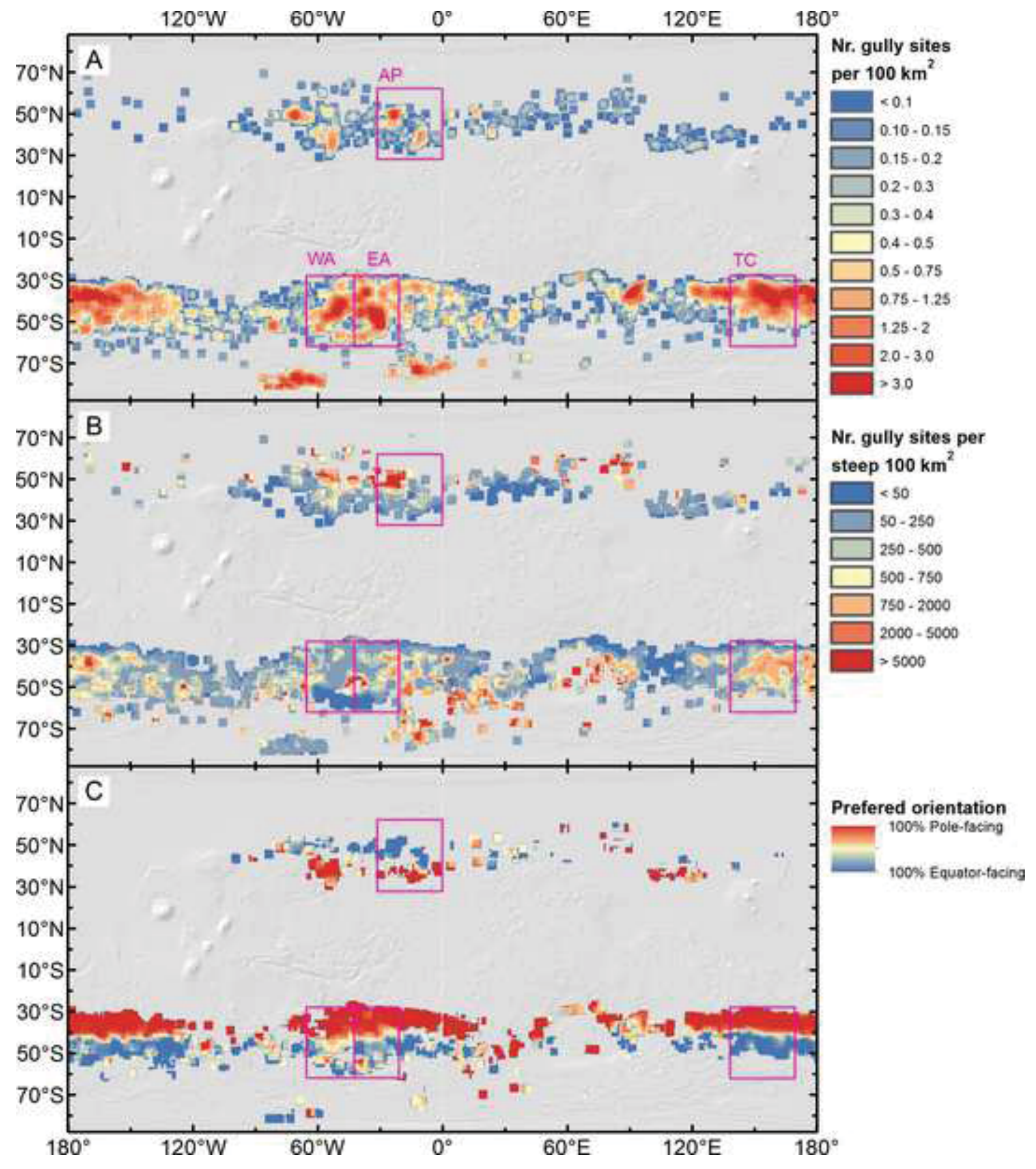




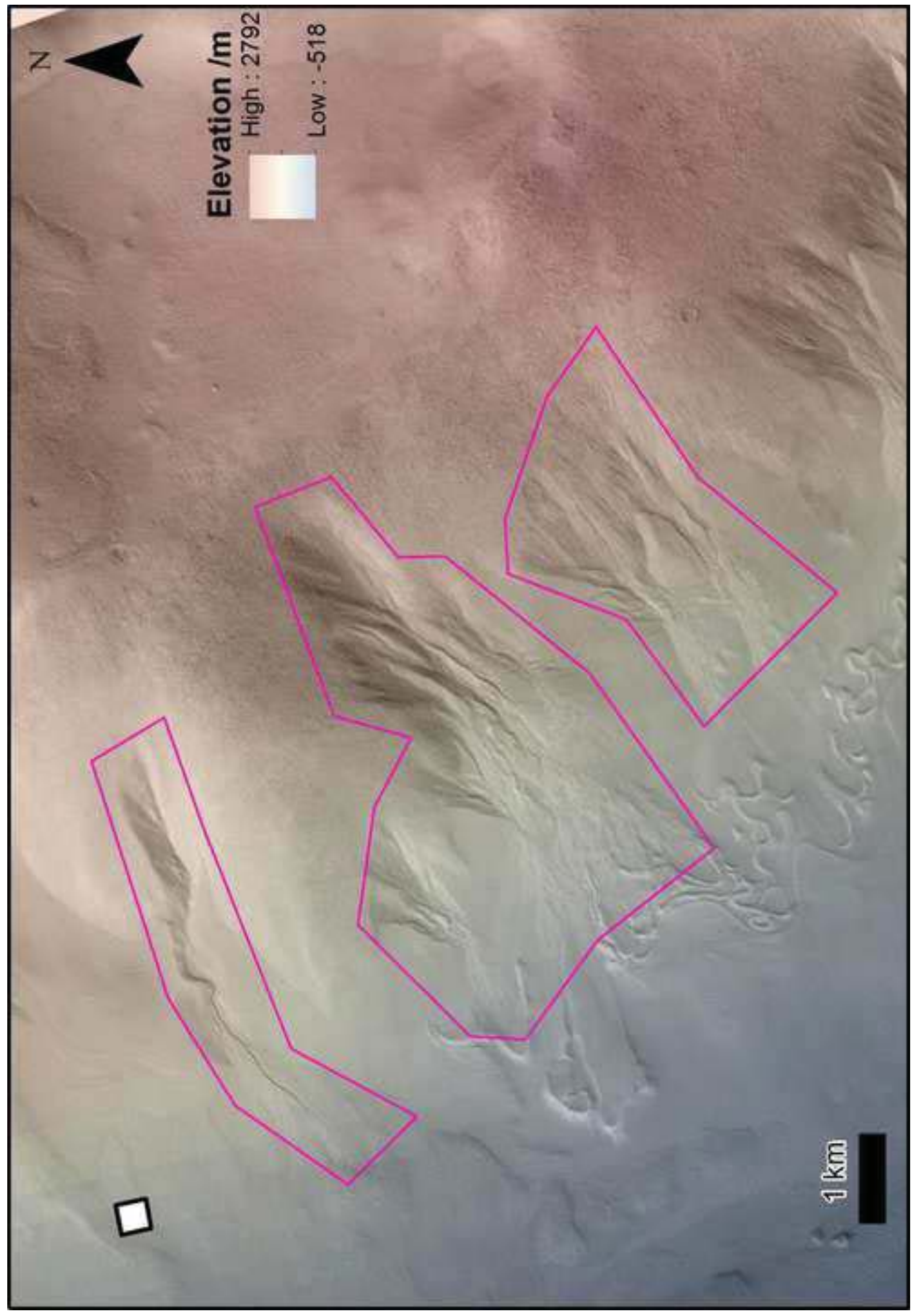



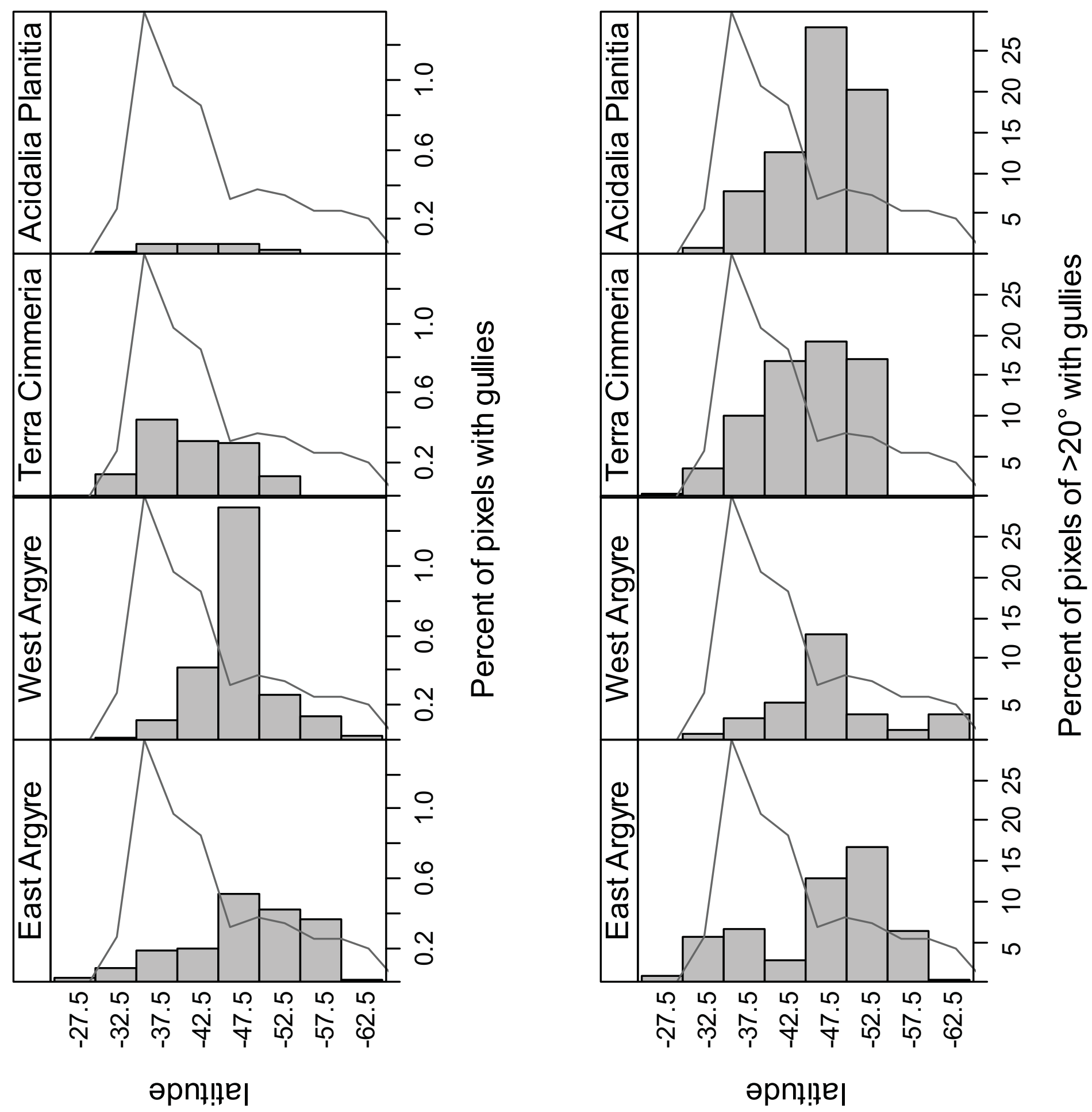

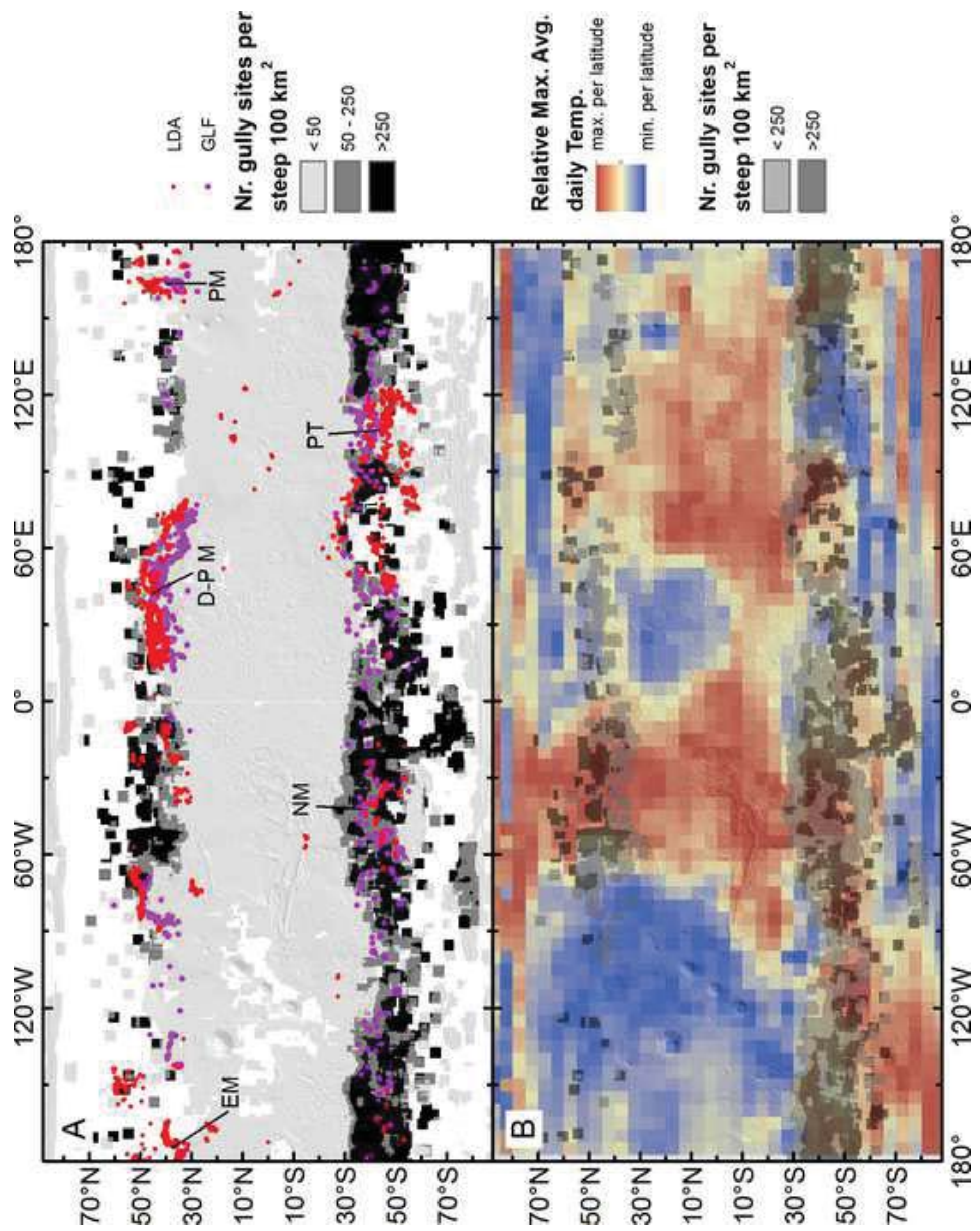